\title{
Postsynaptic Density-95 Mimics and Occludes Hippocampal Long-Term Potentiation and Enhances Long-Term Depression
}

\author{
Valentin Stein, ${ }^{1}$ David R. C. House, ${ }^{1}$ David S. Bredt, ${ }^{2}$ and Roger A. Nicoll ${ }^{1,2}$ \\ Departments of ${ }^{1}$ Cellular and Molecular Pharmacology, and ${ }^{2}$ Physiology, University of California, San Francisco, California 94143
}

\begin{abstract}
Previous studies have shown that overexpression of the protein PSD-95 (postsynaptic density-95) selectively enhances AMPA receptormediated synaptic responses in hippocampal pyramidal cells. To determine whether this effect is related to synaptic plasticity at these synapses, we examined whether PSD-95 expression mimics long-term potentiation (LTP), and also whether it influences LTP and long-term depression (LTD) in hippocampal slice cultures. Using simultaneous recording from transfected or infected cells and control pyramidal cells, we found that PSD-95, similar to LTP, increases the amplitude and frequency of miniature EPSCs. It also converts silent synapses to functional synapses, as does LTP. In addition, LTP is completely occluded in cells expressing PSD-95, whereas LTD is greatly enhanced. These results suggest that common mechanisms are involved in controlling synaptic AMPA receptors by PSD-95 and synaptic plasticity.
\end{abstract}

Key words: PSD-95; AMPA receptors; long-term potentiation; long-term depression; hippocampus; silent synapses

\section{Introduction}

Recent studies have demonstrated that synaptic AMPA receptors, in contrast to NMDA receptors, are highly dynamic. AMPA receptors cycle constitutively into and out of the synapses. Furthermore, NMDA receptor activation can control both the synaptic delivery and removal of AMPA receptors (Malenka and Nicoll, 1999; Ziff, 1999; Scannevin and Huganir, 2000; Malinow and Malenka, 2002; Sheng and Kim, 2002). El-Husseini et al. (2000) and others (Ehrlich and Malinow, 2002; Beique and Andrade, 2003) have found that the protein PSD-95 (postsynaptic density95) regulates synaptic AMPA receptors. Expression of PSD-95 increases the number of synaptic AMPA receptors, and this mechanism requires the interaction of PSD-95 with the tetraspanning AMPA receptor-trafficking protein stargazin (Chen et al., 2000; Schnell et al., 2002). In addition, acutely diminishing the levels of synaptic PSD-95 decreases the number of synaptic AMPA receptors (El-Husseini A et al., 2002). These experiments raise the possibility that the PSD-95-stargazin-trafficking mechanism of AMPA receptors might also play a role in the activitydependent changes in synaptic strength that are initiated by NMDA receptor activation. We examined this possibility by studying the effects of PSD-95 on the ability to induce long-term potentiation (LTP) and long-term depression (LTD). During this

Received March 14, 2003; revised April 24, 2003; accepted April 28, 2003.

This research was supported by grants from the National Institutes of Health (D.S.B. and R.A.N.), the Christopher Reeves Paralysis Foundation (D.S.B.), the Human Frontier Research Program (D.S.B.), and the Bristol-Myers Squibb Company (R.A.N.). V.S. is supported by a grant from the Deutsche Forschungsgemeinschaft (Emmy Noether Programm). R.A.N. is a member of the Keck Center for Integrative Neuroscience and the Silvo Conte Center for Neuroscience Research. D.S.B. is an established investigator for the American Heart Association.

Correspondence should be addressed to Roger A. Nicoll, Department of Cellular and Molecular Pharmacology, University of California San Francisco, San Francisco, CA 94143.

Copyright $\odot 2003$ Society for Neuroscience $\quad$ 0270-6474/03/235503-04\$15.00/0 study, Beique and Andrade (2003) reported that expression of PSD-95 enhances LTD in neurons of the cerebral cortex. In addition, Ehrlich and Malinow (2002) reported that expression of PSD-95 occludes LTP.

\section{Materials and Methods}

Rat hippocampal slice cultures were prepared as described previously (Schnell et al., 2002). PSD-95-GFP (green fluorescent protein) (Schnell et al., 2002) was expressed either by transfection with the Helios Gene Gun (Bio-Rad Laboratories, Hercules, CA), using $1.0 \mu \mathrm{m}$ gold particles coated with DNA according to the protocol of the manufacturer, or by viral infection. PSD-95-GFP was cloned into pSCA1 (DiCiommo and Bremner, 1998). Semliki forest viral particles were produced by transfecting pSCA1-PSD-95-GFP and pHelper in a 1:1 molar ratio into human embryonic kidney 293 (HEK293) cells. The supernatant was harvested $36-48 \mathrm{hr}$ after transfection, aliquoted, and stored at $-80^{\circ} \mathrm{C}$. Before infection, the virus was activated by chymotrypsin treatment for $45 \mathrm{~min}$. Virus solution was injected near CA3 using a Nanoject (Drummond, Burton, $\mathrm{OH}$ ). Recordings were made from CA3 cells $2-4 \mathrm{~d}$ after transfection or within $2 \mathrm{~d}$ of infection, using 2-3 $\mathrm{M} \Omega$ glass electrodes filled with an internal solution consisting of the following (in $\mathrm{mM}$ ): 115 $\mathrm{CsMeSO}_{3}, 20 \mathrm{CsCl}, 10$ HEPES, $2.5 \mathrm{MgCl}_{2}, 4 \mathrm{Na}_{2}$-ATP, $0.4 \mathrm{Na}-\mathrm{GTP}, 10$ Na-phosphocreatine, 0.6 EGTA, and 0.1 spermine, $\mathrm{pH}$ 7.2. External perfusion medium consisted of (in mM): $119 \mathrm{NaCl}, 2.5 \mathrm{KCl}, 2.5 \mathrm{CaCl}_{2}, 1.3$ $\mathrm{MgSO}_{4}, 2.7 \mathrm{MgCl}_{2}, 1 \mathrm{NaH}_{2} \mathrm{PO}_{4}, 26.2 \mathrm{NaHCO}_{3}$, and 11 glucose, saturated with $95 \% \mathrm{O}_{2}$ and $5 \% \mathrm{CO}_{2}$, and included $100 \mu \mathrm{M}$ picrotoxin, $20 \mu \mathrm{M}$ bicuculline and 5-20 $\mu \mathrm{M} 2-\mathrm{Cl}$ adenosine to block inhibition and suppress epileptiform activity. In the minimal stimulation experiments, release probability was further reduced by the addition of the $\mathrm{GABA}_{\mathrm{B}}$ receptor agonist baclofen $(50 \mu \mathrm{M})$. This ensured that on average, both cells received similar numbers of activated synapses. Transfected or infected pyramidal cells were identified using fluorescence microscopy. A tungsten bipolar stimulating electrode was placed in the stratum radiatum. Recording electrodes were used to first establish cell-attached connec- 
tions with both a transfected or infected cell and an immediately adjacent control cell under visual guidance (40×; differential interference contrast optics). Both cells were broken into simultaneously, and stimulation intensity was adjusted until EPSCs were elicited from both cells. Series resistances were monitored during the experiment and typically ranged from 8 to $12 \mathrm{M} \Omega$. A cell pair was discarded if the series resistances differed substantially between the two cells. The collection and analysis of the minimal stimulation data are as described previously (Isaac et al., 1995). The noise amplitude distribution was estimated using the same duration window (5-10 msec) used for measuring EPSCs, but was performed on the trace before the stimulus. Failure rates were estimated using the methods of Liao et al. (1995). Briefly, the number of responses with an amplitude of $>0 \mathrm{pA}$ was determined, and this value was then doubled to produce the failure rate. The ability to generate LTP in control cells in transfected or infected slices varied to some extent across slices but very little from cells within the same slices. For instance, simultaneous recording from pairs of control cells demonstrated that if one cell showed LTP, the other cell had a $>80 \%$ chance of also showing LTP $(n=10)$. In addition, we compared the ability to induce LTP in control and GFPexpressing cells. In all pairs in which the control neuron expressed LTP, the GFP-expressing neurons also expressed LTP $(n=6)$. Thus, for the LTP experiments, we selected for analysis those pairs in which the control cell expressed LTP. For the LTD experiments, all pairs were included for analysis. Tetrodotoxin $(0.5 \mu \mathrm{M})$ was added to the medium in the experiments designed to record miniature EPSCs (mEPSCs). To increase the frequency of events, $50 \mathrm{~mm}$ sucrose was also added to the medium.

\section{Results}

We used the hippocampal slice culture to express PSD-95 in pyramidal cells. PSD-95 was expressed either by biolistics or by viral infection. Although no obvious difference was found in the results for these two methods, the yield of infected neurons with viral infection was much greater than that obtained with biolistic transfection. In confirmation of previous results, AMPA EPSCs were consistently larger in PSD-95-expressing cells compared with control cells (4.1-fold \pm 0.6 -fold, $n=24$ for transfection; 3.9 -fold \pm 0 . 4 -fold, $n=21$ for infection). LTP is associated with an increase in quantal size and frequency (Oliet et al., 1996); therefore, if the PSD-95 enhancement involves a mechanism similar to that underlying LTP, one might expect PSD-95 to increase the amplitude and frequency of mEPSCs. Although PSD-95 increased the amplitude and frequency of mEPSCs in dissociated hippocampal cultures (El-Husseini et al., 2000), overexpression of PSD-95 in the cerebral cortex increased the frequency but not the amplitude of mEPSCs (Beique and Andrade, 2003). Here, we examined the effect of expressing PSD-95 on mEPSCs in the hippocampal slice culture. The mEPSCs were collected from control and PSD-95-expressing cells in the presence of tetrodotoxin, which blocks action potential-dependent release. Sample superimposed records from a control cell and a PSD-95-expressing cell (Fig. $1 A$ ) show that the amplitude of mEPSCs is larger in a PSD95-expressing cell compared with a control cell. In Figure $1 B$, all of the events are plotted as a cumulative frequency distribution and show that the distribution is shifted to larger amplitudes in the PSD-95-expressing cells. This is particularly dramatic at the higher end of the distribution. There was also a fourfold increase in the frequency of mEPSCs in the PSD-95-expressing cells $(3.0 \pm 0.5 \mathrm{~Hz} ; n=7)$ compared with control cells $(0.8 \pm 0.2 \mathrm{~Hz}$; $n=7$ ) (Beique and Andrade, 2003).

One explanation for the increase in MEPSC frequency is that PSD-95 has added AMPA receptors to silent synapses, as is postulated to occur during LTP (Isaac et al., 1995; Liao et al., 1995). We directly examined this possibility by using minimal stimulation and simultaneously comparing the failure rate in control and PSD-95-expressing cells. As shown in the superimposed records
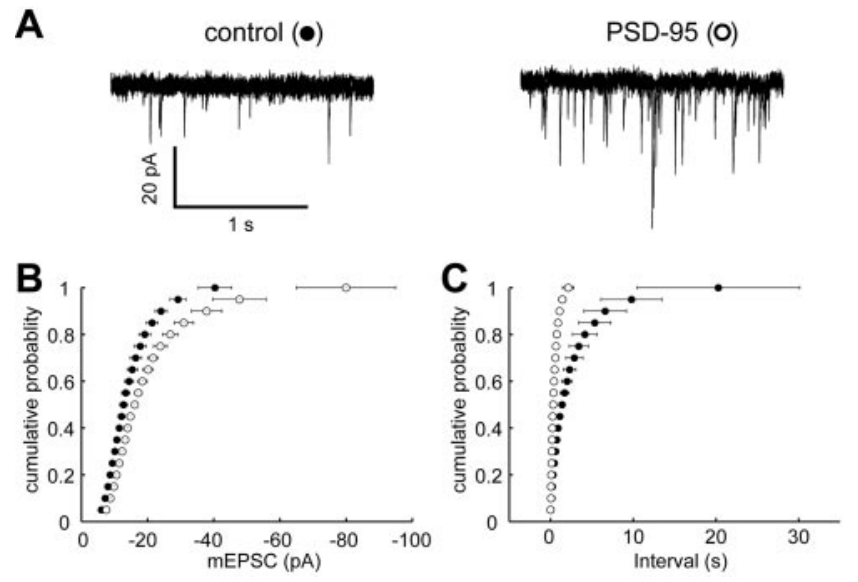

Figure 1. Expression of PSD-95 enhances the amplitude and frequency of $m E P S C$. $A$, Five superimposed sample traces showing mEPSCs from a control cell (left) and a PSD-95-expressing cell (right). Note that there are many more events in the PSD-95-expressing cell, and that some of the events are larger than events recorded in a control cell. $B$, Cumulative frequency distributions of the amplitudes of mEPSCs recorded from control cells (closed circles) and PSD-95expressing cells (open circles) ( $n=7$ ). C, Cumulative frequency distributions of the interevent intervals of mEPSCs recorded in control cells (closed circles) and PSD-95-expressing cells (open circles).

in Figure $2 A$, the failure rate is much reduced in the PSD-95expressing cell, and as expected, the average size of the EPSC is greatly enhanced. To ensure that this result was not simply attributable to the PSD-95-expressing cell receiving more synaptic inputs, we compared the size of the NMDA component of the EPSC at positive potentials in the two cells (Fig. $2 \mathrm{~B}$ ). In five pairs of cells in which the NMDA component was comparable in the two cells, the average failure rate was $82 \pm 5 \%$ in control cells and $35 \pm 5 \%$ in PSD-95-expressing cells.

Because the enhancement of synaptic transmission by PSD-95 shares many of the properties associated with LTP, we examined the possibility that the PSD-95 enhancement occluded LTP. For these experiments, we recorded simultaneously from a PSD-95expressing cell and a neighboring control cell. After collecting baseline responses at $0.2 \mathrm{~Hz}$ for $2 \mathrm{~min}$, both cells were held at $-5 \mathrm{mV}$ and 120 stimuli were delivered at $2 \mathrm{~Hz}$. Both cells were then returned to their original holding potential, and the stimulation rate was returned to $0.2 \mathrm{~Hz}$. As shown in Figure $3 A$, the responses recorded in the cells expressing PSD-95 returned to the baseline within a few minutes after pairing, whereas neighboring control cells exhibited robust LTP. Traces from a typical experiment are shown in Figure 3B. None of the 10 PSD-95-expressing cells, including five with biolistics and five with viral infection, showed any LTP. Because loss of LTP was seen with both methods, it is unlikely that the lack of LTP is secondary to nonspecific effects that might be related to the method of gene delivery. Furthermore, we found that similar magnitudes of LTP were observed in cells expressing GFP compared with control cells.

We next examined whether expression of PSD-95 affects LTD induction. Baseline responses were obtained for a $5 \mathrm{~min}$ period at $0.2 \mathrm{~Hz}$ stimulation. Cells were then held at $-50 \mathrm{mV}$, stimulated at $1 \mathrm{~Hz}$ for $10 \mathrm{~min}$, and then returned to their original holding potential. In our slice culture preparation, LTD was very small in control cells using this protocol (Fig. 4). However, robust LTD was recorded in every neuron expressing PSD-95.

\section{Discussion}

The present results demonstrate that delivery of AMPA receptors to the synapse by PSD-95 shares many properties with LTP. That 

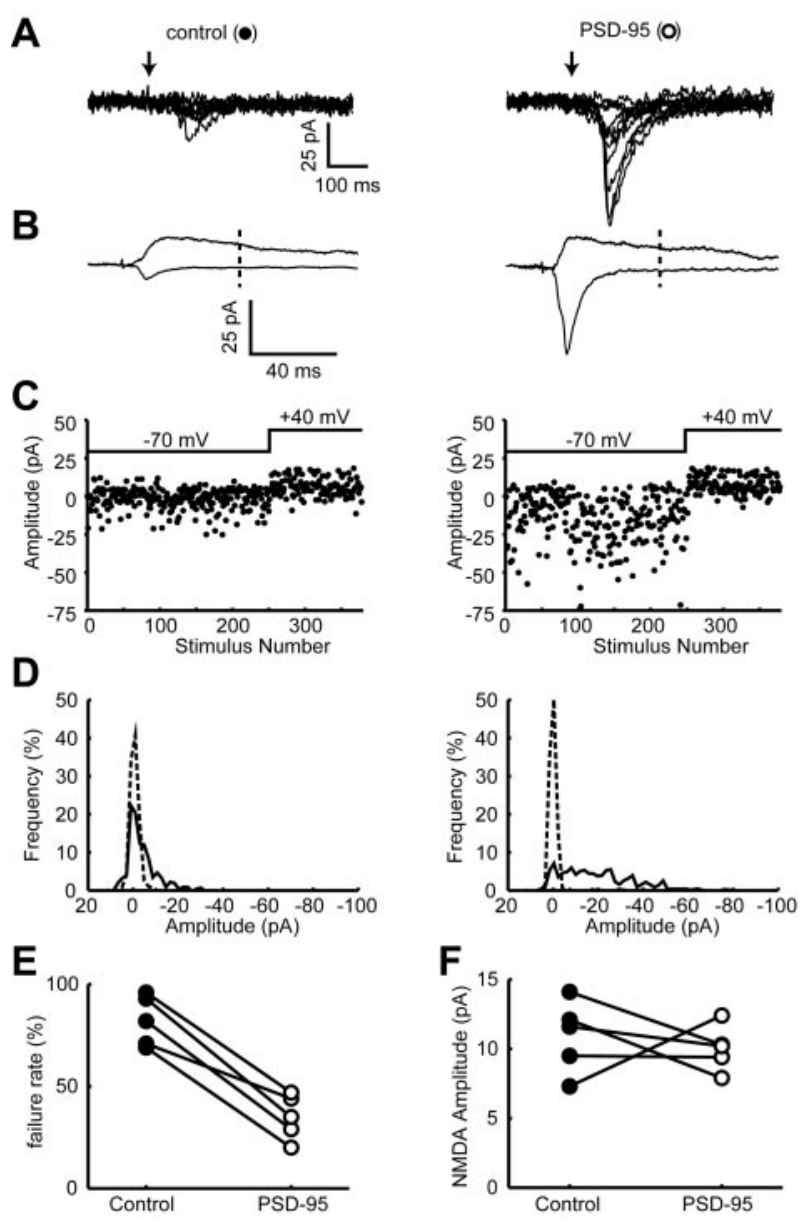

Figure 2. Expression of PSD-95 inserts AMPA receptors into silent synapses. $A$, Ten superimposed traces showing responses to minimal stimulation from a control cell (left) and a PSD-95expressing cell (right). Arrows indicate when the stimulus was delivered. Note that there are many fewer failures, and that the responses are much larger in the PSD-95-expressing cell. $B$, Averaged records of all traces at -70 and $+40 \mathrm{mV}$. Note that the NMDA component is the same in the two cells, whereas the AMPA component is much larger in the PSD-95-expressing cell. The NMDA component was measured 55 msec after the stimulus, as indicated by the dashed line. $C$, Plots of EPSC amplitude versus trial number at -70 and $+40 \mathrm{mV}$ for the control cell (left) and PSD-95-expressing cell (right). D, EPSC amplitude distribution (solid line) and noise (broken line) in the control cell (left) and the PSD-95 expressing cell (right). See Materials and Methods for calculating noise. E, A pair-wise comparison of the failure rate between control and PSD-95expressing cells. See Materials and Methods for estimating failure rate. $F$, A pair-wise comparison of the size of the NMDA EPSC recorded at $+40 \mathrm{mV}$. The symbol for each pair is the same as that used in $E$.

is, expressing PSD-95 enhances both the amplitude and frequency of mEPSCs, as has been reported previously for LTP (Oliet et al., 1996). This enhancement is also consistent with previous studies of PSD-95 expression in dissociated hippocampal neurons (El-Husseini et al., 2000). The increase in amplitude indicates that more AMPA receptors are added to individual excitatory synapses. The increase in frequency of mEPSCs could be attributable to three mechanisms. First, the classical interpretation is an increase in the presynaptic release of quanta. This interpretation cannot explain our results, because previous studies in slice culture found no change in either the NMDA receptor component of the EPSC or in paired-pulse facilitation in cells expressing PSD-95 (Schnell et al., 2002; Beique and Andrade, 2003). Both of these parameters should change if transmitter release is enhanced. Second, the changes could be secondary to the increased amplitude of the mEPSCs. Under control condi-

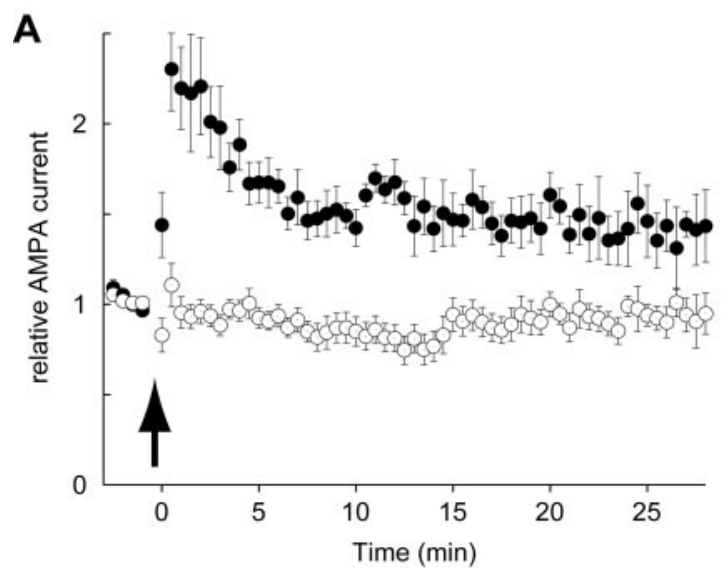

B
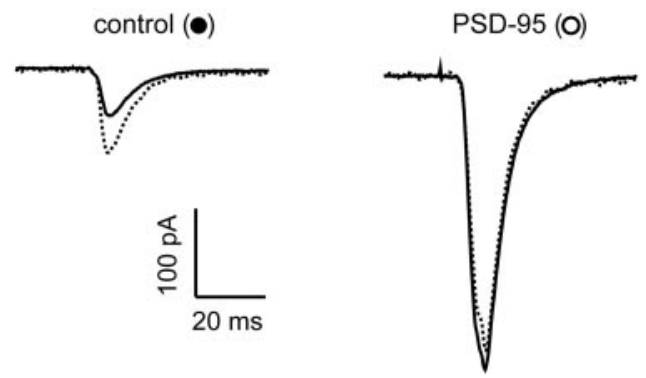

Figure 3. Expression of PSD-95 occludes LTP. A, Graph comparing LTP recorded simultaneously from control neurons (closed circles) and neurons expressing PSD-95 (open circles). The number of cells for both graphs is initially 10 and decreases to five by the end. Arrow indicates the time of pairing. B, Sample records from a pair of neurons showing EPSCs recorded before pairing (solid lines) and after pairing (dotted lines).

tions, it is reasonable to assume that a subset of mEPSCs has amplitudes below the threshold of detection. Increasing the amplitude of mEPSCs will shift some of this undetected population above threshold. This mechanism could explain why the shift in the cumulative amplitude frequency distribution is more striking at larger amplitudes. Third, expression of PSD-95 could deliver AMPA receptors to synapses lacking AMPA receptors (i.e., silent synapses) (Isaac et al., 1995; Liao et al., 1995). Although the second mechanism may well contribute to the increased frequency, the dramatic increase in frequency strongly suggests that PSD-95 delivers AMPA receptors to silent synapses. It has been reported recently that expression of PSD-95 in cerebral cortical neurons increases the frequency of mEPSCs but not their amplitude (Beique and Andrade, 2003). This difference might be explained in part by the fact that the enhancement in evoked EPSCs in the hippocampus by PSD-95 is considerably larger that that found in the cerebral cortex.

We directly tested the unsilencing of synapses by using minimal stimulation and comparing the failure rate between control and PSD-95-expressing cells. Although the size of the NMDA component was the same in the cell pairs, the failure rate was much diminished in the PSD-95-expressing cells. The fact that the NMDA component was the same in the cell pairs rules out both a presynaptic basis for the change in failures and a difference in the number of synapses contacting the two cells. Thus, similar to LTP, it can be concluded that PSD-95 inserts AMPA receptors into previously silent synapses and adds AMPA receptors to AMPA receptor-containing synapses.

Given the close mimicry of the action of PSD-95 with LTP, we looked for an interaction between these two forms of synaptic 

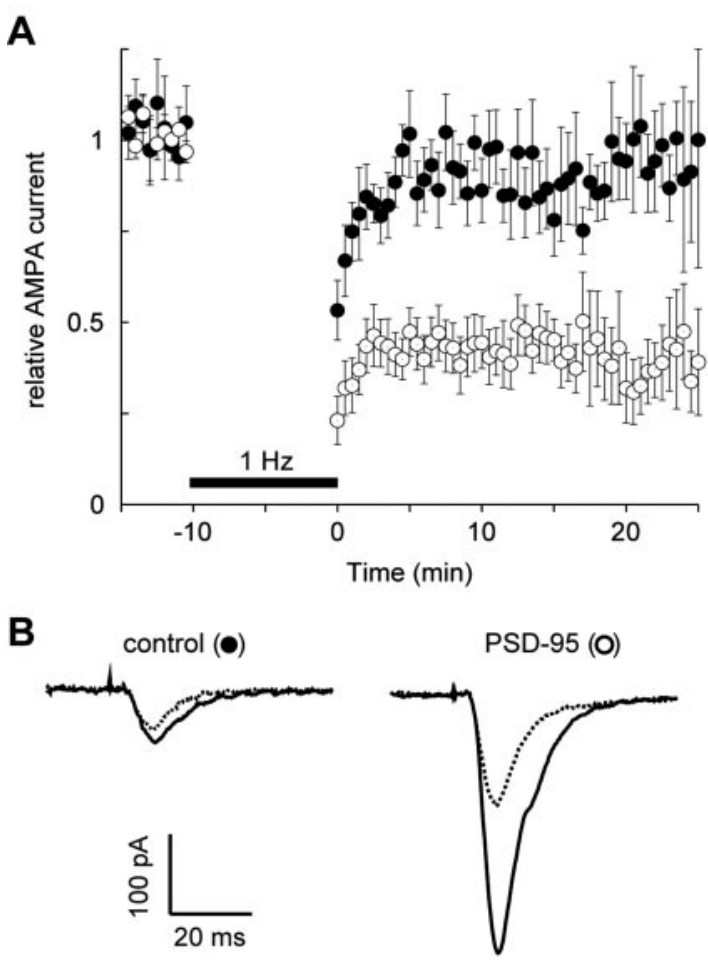

Figure 4. Expression of PSD-95 enhances LTD. A, Graph comparing LTD recorded simultaneously from control neurons (closed circles) and from neurons expressing PSD-95 (open circles). The number of cells for the control graph is initially 11 and decreases to six by the end of the experiments. For the graph of the cells expressing PSD-95, the number of cells is initially 11 and decreases to five by the end of the experiment. $B$, Sample records from a pair of neurons showing EPSCs recorded before pairing (solid lines) and after pairing (dotted lines).

enhancement. Indeed, expression of PSD-95 occluded the ability to generate LTP. This effect was seen both with transfection and infection. In contrast to LTP, the induction of LTD was greatly enhanced in cells expressing PSD-95. These results, along with recent data from others (Ehrlich and Malinow, 2002; Beique and Andrade, 2003), are complementary to previous results in which the targeted disruption of PSD-95 diminished LTD but enhanced LTP (Migaud et al., 1998).

The mechanism by which PSD-95 interacts with synaptic plasticity remains to be elucidated. Two general models can be considered. First, PSD-95 could be directly involved in the process of AMPA receptor delivery and removal during LTP and LTD, respectively. Although this remains a possibility, additional experiments will be needed to determine how PSD-95 fits into the current models of AMPA receptor trafficking during LTP and LTD. A second and equally plausible mechanism is that the delivery of AMPA receptors to the synapse by PSD-95 could be independent and downstream of the trafficking during LTP and LTD. In this scenario, the loading of the synaptic membrane (both silent and nonsilent synapses) with AMPA receptors (and perhaps associated slots) by PSD-95 expression would leave no room for additional AMPA receptors that would be inserted during LTP. However, this abundance of synaptic AMPA receptors would provide a pool of receptors not previously available for removal by LTD. Regardless of the precise mechanism, the present findings emphasize the key role that synaptic AMPA receptors play in LTP and LTD. Furthermore, they demonstrate that simply changing the number of AMPA receptors at the synapse profoundly shifts the threshold balance between LTP and LTD.

\section{References}

Beique JC, Andrade R (2003) PSD-95 regulates synaptic transmission and plasticity in rat cerebral cortex. J Physiol (Lond) 546:859-867.

Chen L, Chetkovich DM, Petralia RS, Sweeney NT, Kawasaki Y, Wenthold RJ, Bredt DS, Nicoll RA (2000) Stargazin regulates synaptic targeting of AMPA receptors by two distinct mechanisms. Nature 408:936-943.

DiCiommo DP, Bremner R (1998) Rapid, high level protein production using DNA-based Semliki Forest virus vectors. J Biol Chem 273:18060-18066.

Ehrlich ID, Malinow R (2002) PSD-95 mimics, occludes and dominant negative forms block LTP in hippocampal slice cultures. Soc Neurosci Abstr 28:713.2.

El-Husseini AE, Schnell E, Chetkovich DM, Nicoll RA, Bredt DS (2000) PSD-95 involvement in maturation of excitatory synapses. Science 290:1364-1368.

El-Husseini AE, Schnell E, Dakoji S, Sweeney N, Zhou Q, Prange O, GauthierCampbell C, Aguilera-Moreno A, Nicoll RA, Bredt DS (2002) Synaptic strength regulated by palmitate cycling on PSD-95. Cell 108:849-863.

Isaac JT, Nicoll RA, Malenka RC (1995) Evidence for silent synapses: implications for the expression of LTP. Neuron 15:427-434.

Liao D, Hessler NA, Malinow R (1995) Activation of postsynaptically silent synapses during pairing-induced LTP in CA1 region of hippocampal slice. Nature 375:400-404

Malenka RC, Nicoll RA (1999) Long-term potentiation: a decade of progress? Science 285:1870-1874.

Malinow R, Malenka RC (2002) AMPA receptor trafficking and synaptic plasticity. Annu Rev Neurosci 25:103-126.

Migaud M, Charlesworth P, Dempster M, Webster LC, Watabe AM, Makhinson M, He Y, Ramsay MF, Morris RG, Morrison JH, O’Dell TJ, Grant SG (1998) Enhanced long-term potentiation and impaired learning in mice with mutant postsynaptic density-95 protein. Nature 396:433-439.

Oliet SH, Malenka RC, Nicoll RA (1996) Bidirectional control of quantal size by synaptic activity in the hippocampus. Science 271:1294-1297.

Scannevin RH, Huganir RL (2000) Postsynaptic organization and regulation of excitatory synapses. Nat Rev Neurosci 1:133-141.

Schnell E, Sizemore M, Karimzadegan S, Chen L, Bredt DS, Nicoll RA (2002) Direct interactions between PSD-95 and stargazin control synaptic AMPA receptor number. Proc Natl Acad Sci USA 99:13902-13907.

Sheng M, Kim MJ (2002) Postsynaptic signaling and plasticity mechanisms. Science 298:776-780.

Ziff EB (1999) Recent excitement in the ionotropic glutamate receptor field. Ann NY Acad Sci 868:465-473. 